\title{
Therapeutic response and safety of the topical, sequential use of antiseptic, keratolytic, and pentamidine creams (3-PACK) on Leishmania (Viannia) braziliensis-infected mice
}

\author{
Betsy Yaneth Muñoz ${ }^{1}$, Julio Cesar Mantilla², Patricia Escobar¹/+ \\ ${ }^{1}$ Universidad Industrial de Santander, Escuela de Medicina, Centro de Investigaciones en Enfermedades Tropicales, \\ Departamento de Ciencias Básicas, Bucaramanga, Colombia \\ ${ }^{2}$ Universidad Industrial de Santander, Escuela de Medicina, Departamento de Patología, Grupo de Investigación en Patología Estructural, \\ Funcional y Clínica, Bucaramanga, Colombia
}

BACKGROUND Topical treatment of New World cutaneous leishmaniasis can be affected by bacterial coinfection, hyperkeratosis, and transdermal drug delivery.

OBJECTIVE The aim of this work was to evaluate the therapeutic response and safety of the topical, sequential use of antiseptic, keratolytic, and pentamidine isethionate (PMD) creams (3-PACK kit) on CL-infected BALB/c mice.

METHODS A $0.5 \%$ chlorhexidine solution (CGH), $10 \%$ salicylic acid (SA), and 3\% or $6 \%$ PMD were used as antiseptic, keratolytic, and antileishmanial drugs, respectively. During the first seven days, antiseptic, followed by $10 \%$ SA gel and PMD cream, were applied topically. Subsequently, treatment was performed only with the antiseptic and PMD creams. Skin irritation, reduction of lesion size $\left(\mathrm{mm}^{2}\right)$, and parasitic load were observed until 30 days of treatment were completed.

FINDINGS The 3-PACK treatment using 6\% PMD induced a complete lesion reduction in 3/6 mice and a partial reduction in $1 / 6$ mice, with no parasites observed. In contrast, CGH and SA alone, along with the vehicle, were not effective $(\mathrm{p}<0.05)$. Moderate to severe erythema was observed at the application site.

MAIN CONCLUSION The topical 3-PACK using 6\% PMD was 67\% effective in the treatment of CL by Leishmania (Viannia) braziliensis. Currently, work is ongoing to improve PMD isethionate formulation and to determine a dose-response.

Key words: Leishmania (Viannia) braziliensis - New World cutaneous leishmaniasis - pentamidine isethionate - antiseptic - keratolytic $\mathrm{BALB} / \mathrm{c}$ mice

New World cutaneous leishmaniasis (NW-CL) is the most common form of leishmaniasis in Latin America. (1) It is caused by intracellular protozoa from the genus Leishmania (Viannia and Leishmania subgenera) and is transmitted by the bite of Lutzomyia sand flies. It primarily occurs in countries such as Brazil, Colombia, Guatemala, and Peru, with roughly 67,000 new clinical cases per year. (1) Cutaneous lesions progress from early papular and nodular lesions to an ulcerated painless nodule of various sizes, with raised edges and a granular bottom, culminating in unaesthetic scars. ${ }^{(2)}$ Cutaneous lesions are usually co-infected with bacteria, and in terms of histology, different percentages of epidermal hyperplasia and thickening of the stratum corneum (acanthosis and hyperkeratosis) have been observed. ${ }^{(3,4)}$
Treatment is recommended to prevent spread, to accelerate the healing process for slow-to-heal lesions [the spontaneous cure rate is only $6.4 \%$ for $L$. (V.) braziliensis], and to prevent disfiguring lesions or scars. ${ }^{(5,6,7,8)}$ Treatment regimens for NW-CL include pentavalent antimonials (systemic or local), oral miltefosine (MTF), pentamidine isethionate, and amphotericin B deoxycholate (or liposomal AMB). ${ }^{(6,8)}$ High cost, rate of adverse events, length of treatment, availability, and relapses are significant drawbacks for many of these treatments. Local therapies are an attractive alternative for some CL cases, especially when systemic treatment is contraindicated. ${ }^{(6,8)}$ These include thermotherapy, intralesional antimonies, and topical drug preparations such as paromomycin plus $12 \%$ methylbenzethonium or $0.5 \%$ gentamicin (called WR 279,396). ${ }^{(6,7,8,9)}$

The 3-PACK kit is a three-component treatment consisting of an antiseptic, a keratolytic, and an antileishmanial cream. Chlorhexidine digluconate (CHG), the antiseptic of choice, is a biguanide disinfectant and skin antiseptic compound that is effective against a wide range of bacteria, viruses, and yeasts. ${ }^{(10)}$ Salicylic acid (SA) is a lipid-soluble organic compound that can penetrate lipid membranes and decrease corneocyte cohesion. ${ }^{(1)}$ Pentamidine (PMD) isethionate, the selected antileishmanial drug, is a synthetic diamidine derivative and cationic drug that is commercially available as diisethionate salt (Pentacarinat $\left.{ }^{\circledR}\right) \cdot{ }^{(12)}$ PMD's main target is thought to be the parasites' mitochondria. Dramatic

Received 13 November 2018

Accepted 21 March 2019 
dilation, condensation, disruption of kinetoplast DNA, and collapse (decrease) of the parasites' mitochondrial membrane potential have been demonstrated after treatment with PMD. ${ }^{(12)}$ PMD isethionate is used as a secondline therapy for treating NW-CL [except for Leishmania (V.) guyanensis infections, for which it is a first-line treatment], ${ }^{(13)}$ and is also recommended for the treatment of Pneumocystis jiroveci pneumonia and early stages of African trypanosomiasis. ${ }^{(14,15)}$ Various doses of this medication (e.g. 2-7 mg/kg/day, 1-7 doses every 2-3 days intramuscularly) have been used for NW-CL, with an overall efficacy of $35-96 \% \cdot{ }^{(16,17,18,19)}$ Systemic use of PMD isethionate has been linked to side effects such as pain, abscesses at the injection site, nausea, vomiting, malaise, myalgia, headache, hypotension, hypoglycaemia, and hyperglycaemia..$^{(16,17,18,19)}$

The ultimate goal of this work is to contribute to the research on topical alternatives for NW-CL treatment; to this end, we aimed to design and evaluate the therapeutic response and safety of the consecutive topical use of an antiseptic, keratolytic, and PMD isethionate cream (3PACK kit) on $L$. (V.) braziliensis-infected mice.

\section{MATERIALS AND METHODS}

Drugs and reagents - Pentamidine isethionate (Pentacarinat ${ }^{\circledR}$, PMD Sanofi-Aventis, Colombia) was supplied by the Secretary of Health of Santander, Colombia. One bottle of Pentacarinat contained $300 \mathrm{mg}$ of PMD diisethionate (171 $\mathrm{mg}$ of PMD). Chlorhexidine digluconate (CHG), SA, and permeants (oleic acid and trans- $\beta$ caryophyllene) were obtained from Sigma-Aldrich (St. Louis, USA). Foetal bovine serum (FBS) and Schneider medium were purchased from Gibco ${ }^{\circledR}$ (Grand Island, NY, USA). Sodium carboxymethyl cellulose (CMC), triple stearic acid, glyceryl monostearate, triethanolamine (TEA), and glycerine were obtained from Suquín Ltda (Colombia). Physicochemical properties and chemical structures of the 3-PACK kit active agents are shown in Supplementary data (Fig. 1).

3-PACK kit preparation - A $0.5 \%$ (v/v) CHG solution was prepared through dilution in $70 \%$ ethyl alcohol. For the SA hydrogel, a CMC solution $(2 \% \mathrm{w} / \mathrm{v})$ was prepared by adding CMC powder $(2.0 \mathrm{~g})$ to $100 \mathrm{~mL}$ of distilled water and stirring at $65^{\circ} \mathrm{C}$ until solubilisation was complete. After CMC dissolution, SA was added by stirring, and the solution was then homogenised for $20 \mathrm{~min}$. A gel without SA was prepared as a vehicle. ${ }^{(20)}$ For the oil-in-water (o/w) PMD isethionate cream, a mixture was prepared of $4.4 \%$ triple pressed stearic acid and $1.4 \%$ Cutina MD (oily phase), and a separate mixture was prepared of TEA, glycerine, water, and excipients (aqueous phase) by melting at $70^{\circ} \mathrm{C}$. After homogenisation, the aqueous phase was added to the oil phase at the same temperature and mixed by continuous stirring for $15 \mathrm{~min}$. After the emulsion was cooled to $27^{\circ} \mathrm{C}$, PMD isethionate (dissolved in DMSO) and permeants were added. In all cases, $0.5 \% \mathrm{w} / \mathrm{v}$ sodium benzoate was added to water as a preservative.

Characterisation of physical parameters - Visual appearance, colour, consistency, and homogeneity were determined. To measure $\mathrm{pH}, 2 \mathrm{~g}$ of each formulation was diluted in $30 \mathrm{~mL}$ of water, and $\mathrm{pH}$ was determined after $1 \mathrm{~h}$ using a digital $\mathrm{pH}$ meter (Ohaus Starter 3100, New Jersey, USA). Regarding $\mathrm{pH}$, values below 7, at 7, and above 7 were considered acidic, neutral, and alkaline, respectively. The cream's viscosity was determined using a viscometer (Brookfield DV2T, Middleboro, USA) at $26^{\circ} \mathrm{C}$, and results were expressed in centipoise (cP). Determinations were performed in triplicate. The stability of organoleptic characteristics and $\mathrm{pH}$ was determined at $4^{\circ} \mathrm{C}, 26^{\circ} \mathrm{C}$, and $37^{\circ} \mathrm{C}$ storage during the first 45 days after preparation.

Parasites - Promastigotes of $L$. (V.) braziliensis $(\mathrm{MHOM} / \mathrm{BR} / 75 / \mathrm{M} 2903)$ were cultured at $26^{\circ} \mathrm{C}$ with weekly serial passages in Schneider medium supplemented with $10 \%$ FCS.

Promastigotes test - Late-growth phase promastigotes at a concentration of $1 \times 10^{6}$ parasites $/ \mathrm{mL}$ were treated with serial 1:3 dilutions of PMD isethionate (in solution and cream form) for $72 \mathrm{~h}$. Control parasites were maintained in medium alone or in vehicles. Inhibition of parasitic growth was determined microscopically by counting live and dead parasites with a haemocytometer. Results were expressed as the concentration needed to inhibit $50 \%$ of parasites $\left(\mathrm{IC}_{50}\right)$, calculated by sigmoidal regression analysis using Msxlfit ${ }^{\mathrm{TM}}$ software (ID Business solution, UK).

Mice - BALB/c mice (8-10 weeks old) were obtained from the National Health Institute (Bogota, Colombia) and housed with a $12 \mathrm{~h} \mathrm{light/dark} \mathrm{cycle} \mathrm{at} 23^{\circ} \mathrm{C}$, with water and food pellets ad libitum. Upon completion of the experiments, animals were anesthetised with intraperitoneal injections of $87.5 \mathrm{mg} / \mathrm{kg}$ ketamine and $12.5 \mathrm{mg} / \mathrm{kg}$ xylazine cocktail, and then euthanised by cervical dislocation.

Ethics - The studies were performed according to the NIH Guide for the Care and Use of Laboratory Animals. Protocols were approved by the Industrial University of Santander ethics committee (Code No. 4110).

\begin{tabular}{|c|c|c|c|c|c|c|c|}
\hline \multirow{2}{*}{\multicolumn{2}{|c|}{$\begin{array}{c}\text { 3-PACK } \\
\text { components }\end{array}$}} & \multicolumn{2}{|c|}{ color } & \multicolumn{2}{|c|}{$\mathrm{pH}$} & \multirow{2}{*}{$\begin{array}{l}\text { Macroscopic } \\
\text { Aspect }\end{array}$} & \multirow{2}{*}{$\begin{array}{l}\text { In vitro activity } \\
\mathrm{IC}_{50}(\mu \mathrm{g} / \mathrm{mL} \text { of } \\
\text { formulation) }\end{array}$} \\
\hline & & $\begin{array}{c}1 \\
\text { day }\end{array}$ & 45 day & $\begin{array}{c}1 \\
\text { day }\end{array}$ & 45 day & & \\
\hline \multicolumn{2}{|c|}{$\begin{array}{c}\text { Antiseptic } \\
0.5 \% \\
\mathrm{CHG}^{3} \text { solution }\end{array}$} & $\mathrm{T}^{\mathrm{d}}$ & T & 7.05 & 7.09 & & $>10000$ \\
\hline \multicolumn{2}{|c|}{$\begin{array}{c}\text { Keratolytic } \\
10 \% \\
\mathrm{SA}^{\mathrm{b}} \text { gel }\end{array}$} & T & T & 6.21 & 6.18 & & $>10000$ \\
\hline \multirow{2}{*}{$\begin{array}{l}\text { PMD } \\
\text { cream }\end{array}$} & $3 \%$ & White & White & 5.15 & 5.2 & & $4.89 \pm 0.8$ \\
\hline & $6 \%$ & White & White & 5.00 & 5.10 & & $0.9 \pm 0.8$ \\
\hline
\end{tabular}

Fig. 1: physical characteristics and in vitro antileishmanial activities of 3-PACK formulations, determined 1 and 45 days after preparation at $\sim 26^{\circ} \mathrm{C}$. In vitro activity against Leishmania (Viannia) braziliensis promastigotes was determined as described in the Materials and Methods section. $a$ : chlorhexidine digluconate; $b$ : salicylic acid; $c$ : pentamidine isethionate; $d$ : translucent. 
Skin irritation test - This was determined in accordance with the Organization for Economic Cooperation and Development guidelines (OECD, 2015). ${ }^{(21)}$ Healthy mice $(\mathrm{N}=2)$ were trichotomised and were topically treated the following day with the antiseptic, the keratolytic, and 3\% or $6 \%$ PMD cream. Signs of oedema or erythema at the application site after 4,24 , and $72 \mathrm{~h}$, and 9- and 14-days post-treatment were registered and scored from $0=$ no irritation to $4=$ severe irritation. Mice were sacrificed, and skin samples were collected for histopathological studies.

Skin (keratolytic effect) - Trichotomised healthy mice $(\mathrm{N}=2)$ were treated daily for seven days with $10 \% \mathrm{SA}$ gel or vehicle. Animals were sacrificed, and skin biopsies were collected. Changes at the application site or at the epidermal level (such as acanthosis, hyperkeratosis, and spongiosis) were determined.

3-PACK activities in infected mice - The following day, mice were shaved and the following day they were subcutaneously inoculated in the rump with $5 \times 10^{5}$ stationary-phase promastigotes. When lesions were visible and large (15-20 weeks after infection), mice were randomly divided into four experimental groups and lesions were treated as follows: Group 1 received 3-PACK treat- ment using 3\% PMD cream $(\mathrm{N}=4)$; Group 2 received 3 -PACK using 6\% PMD cream $(\mathrm{N}=6)$; Group 3 received 3-PACK without PMD cream $(\mathrm{N}=2)$; and Group 4 received 3-PACK vehicles $(\mathrm{N}=3)$. During the first seven days of treatment, antiseptic was applied each day at $5: 45 \mathrm{pm}$, followed after $15 \mathrm{~min}$ by $10 \%$ SA keratolytic gel at $6 \mathrm{pm}$, and finally PMD cream at $6 \mathrm{am}$. Thereafter, treatment consisted only of antiseptic and PMD cream twice a day until 30 days elapsed.

Lesion size was measured weekly using a digital caliper, and area $\left(\mathrm{mm}^{2}\right)$ was calculated. Animals were sacrificed 15 days after finishing the treatment. Impression smears from lesions, livers, and spleens were prepared on glass slides. These were air-dried, fixed with methanol, and stained with Giemsa. Biopsies were also collected for histopathological studies. Body weight and signs of skin irritation were registered each week. Per cent decrease in lesion size $(\% \mathrm{D})$, or improvement in each animal after treatment, was calculated according to the equation 100-[lesion size $\left(\mathrm{mm}^{2}\right)$ after treatment $\mathrm{x}$ 100/lesion size $\left(\mathrm{mm}^{2}\right)$ before treatment], and classified as significant $(75-100 \%)$, moderate $(50-75 \%)$, partial $(25-50 \%)$, or no improvement $(<25 \%)$. In addition, parasites (amastigotes) from lesion smears and biopsies were microscopically scored as absent $(-)$, occasionally present $(+/-)$, or usually present $(+)$.

TABLE

Effect of 3-PACK treatment on cutaneous leishmaniasis (CL)-infected mice. Lesion sizes before treatment and at the end of the experiment (15 days post-treatment) were measured and the percentage decrease in lesion size (\% D) was calculated. Improvement was classified as: significant (S, 75-100\%); moderate (M, 50-75\%); partial (P, 25-50\%); or no improvement (No I, $<25 \%$ ). Parasites on CL lesions after treatment were scored as absent $(-)$, occasionally present $(+/-)$, or usually present $(+)$

\begin{tabular}{|c|c|c|c|c|c|c|c|c|}
\hline \multirow[b]{2}{*}{ Group } & \multirow[b]{2}{*}{ 3-PACK } & \multirow[b]{2}{*}{ Mice (M) } & \multicolumn{2}{|c|}{ Lesion size $\left(\mathrm{mm}^{2}\right)$} & \multicolumn{2}{|c|}{ Lesion (\%) } & \multirow[b]{2}{*}{ Classification } & \multirow[b]{2}{*}{ Parasites } \\
\hline & & & Before & After & Increase & Decrease & & \\
\hline \multirow{4}{*}{1} & \multirow{4}{*}{$3 \% \mathrm{PMD}^{a}$} & M1 & 25.4 & $\mathbf{0}$ & $\mathbf{0}$ & 100 & $\mathbf{S}$ & $(+/-)$ \\
\hline & & M2 & 27.4 & 28.0 & 2.21 & 0 & No I & $(+)$ \\
\hline & & M3 & 13.4 & 46.2 & 32.8 & 0 & No I & $(+)$ \\
\hline & & M4 & 18.8 & 15.5 & $\mathbf{0}$ & 17.4 & No I & $(+/-)$ \\
\hline \multirow{6}{*}{2} & \multirow{6}{*}{$6 \% \mathrm{PMD}^{b}$} & M1 & 33.0 & $\mathbf{0}$ & $\mathbf{0}$ & 100 & $\mathbf{S}$ & $(-)$ \\
\hline & & M2 & 64.32 & 46.5 & 0 & 27.66 & $\mathrm{P}$ & $(-)$ \\
\hline & & M3 & 171.2 & 0 & 0 & 100 & $\mathrm{~S}$ & $(-)$ \\
\hline & & M4 & 186.2 & 0 & 0 & 100 & $\mathbf{S}$ & $(-)$ \\
\hline & & M5 & 22.83 & 70.8 & 48.01 & 0 & No I & $(+/-)$ \\
\hline & & M6 & 9.50 & 8.76 & $\mathbf{0}$ & 7.69 & No I & $(+/-)$ \\
\hline \multirow{2}{*}{3} & \multirow{2}{*}{$0 \% \mathrm{PMD}^{c}$} & M1 & 24.19 & 47.5 & 23.31 & 0 & No I & $(+)$ \\
\hline & & M2 & 20.02 & 51.9 & 31.90 & 0 & No I & $(+)$ \\
\hline \multirow{3}{*}{4} & \multirow{3}{*}{ No 3-PACK ${ }^{d}$} & M1 & 24.91 & 81.4 & 56.52 & 0 & No I & $(+)$ \\
\hline & & M2 & 25.63 & 81.3 & 55.76 & 0 & No I & $(+)$ \\
\hline & & M3 & 32.41 & 85.6 & 53.26 & 0 & No I & $(+)$ \\
\hline
\end{tabular}

$a$ : antiseptic, keratolytic and 3\% pentamidine isethionate cream; $b$ : antiseptic, keratolytic and $6 \%$ pentamidine isethionate cream; $c$ : antiseptic plus keratolytic; $d$ : vehicles. PMD: pentamidine. 


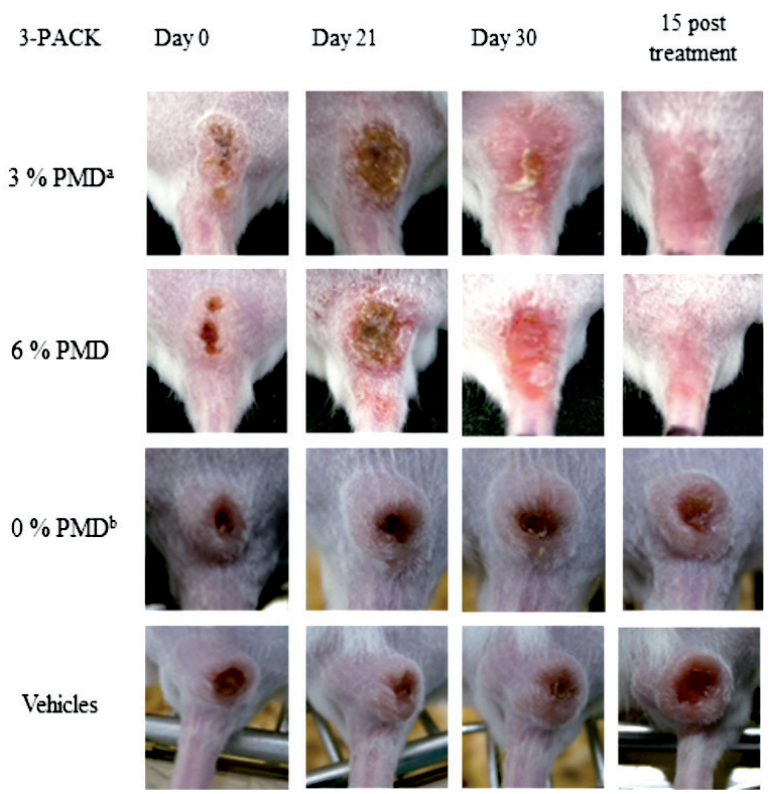

Fig. 2: effect of 3-PACK on BALB/c mice infected with Leishmania (Viannia) braziliensis. Topical treatment was applied for 30 days. This image shows leishmaniasis lesions in each of the groups at the beginning, during, and 15 days after treatment. $a$ : pentamidine isethionate cream; $b$ : antiseptic plus keratolytic.

Histopathological studies - Specimens were fixed in $10 \%$ buffered formalin ( $\mathrm{pH} 7.2$ ), embedded in paraffin, and microtomed. $5-\mu \mathrm{M}$ sections were stained with haematoxylin and eosin, and then microscopically observed. Results were recorded with photomicrographs and the intensities of the different histopathological patterns were semi-quantitatively scored as: $(-)$ negative, $(+)$ discrete, $(++)$ moderate, or $(+++)$ intense.

Statistical analysis - Differences in the mean lesion sizes $\left(\mathrm{mm}^{2}\right)$ among the groups were assessed using the Kruskal-Wallis test. $\mathrm{P}$ values of $<0.05$ were considered statistically significant. All analyses were performed using SigmaStat software version 3.5.

\section{RESULTS}

Physical 3-PACK characterisation - 3-PACK components were easily prepared and their homogeneity and stability were observed over time at different storage temperatures. The antiseptic with $0.5 \% \mathrm{CHG}$ showed a decrease in volume at $37^{\circ} \mathrm{C}$ (probably from alcohol evaporation). Cream viscosity was $147,545.50 \pm 4.87 \mathrm{cP}$. Fig. 1 summarises some of the physicochemical characteristics of the 3-PACK components.

Pentamidine parasite activity - After $72 \mathrm{~h}$ of treatment, PMD isethionate (in solution) was active against $L$. (V.) braziliensis promastigotes, with $\mathrm{IC}_{50}$ values of $0.21 \pm$ $0.1 \mu \mathrm{M}$ (data not shown). Both $3 \%$ and $6 \%$ PMD creams were also active against parasites (Fig. 1), while neither $10 \%$ SA gel nor $0.5 \% \mathrm{CHG}$ were active against parasites.

Skin irritation caused by 3-PACK components in healthy skin - No signs of oedema or erythema were observed after one dose of $0.5 \% \mathrm{CHG}, 10 \% \mathrm{SA}$ gel, and
$3 \%$ or $6 \%$ PMD cream treatment at the evaluated times [Supplementary data (Fig. 2)]. Histologically, any alterations in skin biopsies were registered (data not showed).

Keratolytic effect of $10 \% \mathrm{SA}$ gel on healthy skin - No signs of irritation/corrosion or redness were observed after topical application of $10 \%$ SA gel for seven days. A shedding of the stratum corneum, with no affectation on the other epidermal layers, was observed histologically after 10\% SA gel treatment [Supplementary data (Fig. $3)$ ]. In contrast, no changes in external epidermal layers were observed after treatment with vehicles [Supplementary data (Fig. 3)].

3-PACK efficacy on CL-infected mice - Table shows the individual percentage decreases (improvements) in lesion size and parasite loads 15 days after completing treatment. In Group 1 (3-PACK with 3\% PMD), a complete healing of CL lesions with an occasional presence of parasites $(+/-)$ was observed in one of four mice $(1 / 4)$. In contrast, the 3 -PACK with $6 \%$ PMD treatment (Group 2 ) induced a complete reduction in three of six mice and a partial reduction in one of six mice, with no parasites observed on smears and biopsies (Table). The 3-PACK treatment without PMD (CHG and SA gel only) and the vehicles were not effective, and CL lesions increased more than $20 \%$ in size, with the presence of parasites $(+)$ in smears and biopsies of lesions (Groups 3 and 4, Table). Significant differences $(\mathrm{p}<0.05)$ were found in mice treated with 3-PACK (Groups 1 and 2) compared to the controls (Groups 3 and 4), as shown in Table. Fig. 2 depicts the photographic appearance of lesions during and after 15 days of treatment. Histopathological features after 3-PACK treatment of L. (V.) braziliensis-infected mice are showed in Supplementary data (Fig. 4).

3-PACK irritation (in infected mice) - Irritation at the treatment site (lesions) was evident on treatment day 15. A strong reddening of the lesion and signs of pain (treatment rejection and stress) were observed; grade 3 erythema corresponded to moderate to severe erythema (defined by colour and well-defined area) and grade 0 oedema corresponded to no oedema. Redness continued at a lower intensity until the end of the experiment (Fig. 2). This phenomenon was not evident when $0.5 \% \mathrm{CHG}$ and $10 \% \mathrm{SA}-$ gel were used. To confirm our results, a 6\% PMD cream formulation was prepared under similar conditions, using PMD isethionate from Sigma-Aldrich, and tested $(\mathrm{N}=1$ infected mice). Signs of irritation were also observed 15 days after starting treatment, and consequently we decided to stop the treatment five days later (data not shown).

\section{DISCUSSION}

In this work, a three-component (3-PACK) kit and its application protocol were designed. Each component targeted some of the most important CL lesion characteristics, such as bacterial over-infection, thickening of the epidermis (hyperkeratosis), and parasite loads inside dermal macrophages. A logical, sequential application protocol was used, starting with an antiseptic, followed by a keratolytic, and finishing with the topical application of a highly effective in vitro antileishmanial drug. For the antiseptic, a $0.5 \% \mathrm{CHG}$ alcohol solution was eas- 
ily prepared, stable at $4-25^{\circ} \mathrm{C}$, and non-irritating. Secondary bacterial infection is a common problem in $\mathrm{CL}$ and can worsen the disease by increasing infection time and exacerbating tissue destruction and scarring. ${ }^{(4)}$ Although a relationship between lesion improvement and the simultaneous use of antibiotics with antileishmanial treatment has not been demonstrated, ${ }^{(22)}$ antibiotic treatment before antimonial administration is recommended, especially for NW-CL. ${ }^{(4)}$ Additional studies are recommended to investigate $\mathrm{CHG}$ use for chronic or persistent wounds (as in chronic NW-CL) and its convenience compared to other treatments, i.e. neutral soap and tap water, alcohols, and antibiotics.

The use of a keratolytic agent such as SA for this NW-CL experimental model was a strategy to combat some of the epidermal histological changes present with the disease (i.e. acanthosis and hyperkeratosis) in order to increase PMD skin penetration. SA dissolved well in the CMC-hydrogel and was physicochemically stable. Topical applications of SA have been used to remove excessively cornified skin, including corns and calluses, and to treat systemic forms of hyperkeratosis, such as psoriasis and ichthyosis. ${ }^{(1)}$ In this study, 7 days of $10 \%$ SA treatment induced a reposition of the stratum corneum with no signs of skin irritation. SA was used independently of the antileishmanial drug in order to facilitate their use protocols. The balance between drug permeation and nontoxic, non-irritating, and non-allergenic effects cannot always be achieved; for example, topical paromomycin in combination with $12 \%$ methylbenzethonium chloride (a cationic quaternary ammonium permeant) are related to inflammation and pain. ${ }^{(23)}$

The third 3-PACK component was $3 \%$ or $6 \%$ PMD $\mathrm{o} / \mathrm{w}$ cream formulations. PMD isethionate has been used as a drug option for NW-CL, ${ }^{(16,17,18,19)}$ and parasites from different Leishmania species are also susceptible $\left(\mathrm{IC}_{50}\right.$ around $0.5-7 \mu \mathrm{M}){ }^{(13,19)}$ The parasites used in this study were susceptible to PMD isethionate in solution at similar $\mathrm{IC}_{50}$ doses. For the design of the topical formulation, we used Pentacarinat (300 mg powder), which is recommended for intramuscular or intravenous application in leishmaniasis or for inhalation in the prophylaxis of $P$. jiroveci pneumonia. ${ }^{(14)}$ There is no commercially available topical PMD formulation, and it is difficult to extrapolate in vitro results for an in vivo application. We decided on an initial PMD cream concentration of 3\% PMD isethionate (equivalent to $30 \mathrm{mg} / \mathrm{mL}$ of PMD isethionate) to see how it performed. Drug concentrations contained in other topical formulations tested for CL are diverse, i.e. $15 \%$ (paromomycin, WR 279,396), 5\% (Imiquimod, Aldara), and 3\% (amphotericin B, Anfoleish). ${ }^{(9,24,25)}$

PMD isethionate formulations in this study were easily prepared using triple pressed stearic acid and glyceryl stearate as anionic self-emulsifying bases (amply used in cosmetic and pharmaceutical skin care), and DMSO, oleic acid, and terpenes as skin penetration enhancers. ${ }^{(26)}$ A slightly acidic $\mathrm{pH}$ (a final $\mathrm{pH}$ of 5.15) was selected to prevent PMD precipitation. The PMD cream was stable at the different storage conditions used and no changes in colour and $\mathrm{pH}$, or signs of phase separation, were registered. In addition, its in vitro antileishmanial activity was retained when it was formulated in a cream.
Once the components of the 3-PACK were prepared and characterised, we selected the scheme of use. We decided to use the antiseptic every day and the keratolytic for only seven days (to avoid the potential risk of systemic toxicity). ${ }^{(1)}$ Dosage and frequency of PMD isethionate administration were a main concern. We could not find available data on the skin permeability of PMD isethionate alone, or in conjunction with the current permeants or SA as a keratolytic. In addition, considering its physicochemical properties Supplementary data (Fig. 1), PMD did not meet all the requirements for a drug to penetrate the $\mathrm{SC}$ : poor absorption or permeation is more likely when the molecular weight is greater than $500 \mathrm{~g} /$ mol, the calculated Log $\mathrm{P}$ is greater than 5, and there are more than $5 \mathrm{H}$-bond donors/10 H-bond acceptors. ${ }^{(27)}$ Information about the topical use of pentamidine was scarce. A topical application of 10\% PMD isethionate and $10 \%$ usnic acid cream over eight consecutive days reduced lesion size (reduction of $27.37 \%$ ) and parasite numbers in $L$. (L.) amazonensis-infected hamsters, compared to controls. ${ }^{(28)}$ In addition, intralesional PMD isethionate (three injections of $120 \mu \mathrm{g} / \mathrm{mm}^{2}$ to the lesion area over five days) has resulted in a cure rate of $72 \%$ for Bolivian L. (V.) braziliensis-infected patients. ${ }^{(29)}$

In this study, we used the 3-PACK to treat wellformed CL lesions. The 3-PACK serial treatment using $3 \%$ PMD cream was able to reduce the lesion size by $100 \%$ in one out of four mice; however, $6 \%$ PMD cream was able to completely reduce CL lesions in 3/6 mice and partially reduce lesions in 1/6 mice, with no microscopically-observed parasites on stained smears and biopsies from lesions (efficacy of 67\%). This is a very encouraging result, especially given the mouse model used. As seen in Fig. 2, very well defined lesions (nodule and open ulcer), similar to certain localised-CL lesions in humans, can be induced in mice after $L$. (V.) braziliensis infections. Using the same animal model, we demonstrated both treatment efficacies: 1. any cure (or in vivo antileishmanial effect) after topical usage of ketoconazole or liposomal chlorine aluminum phthalocyanine systems (as photosensitizer for photodynamic therapy) or 2. a complete reduction of lesion and parasite loads (by microscopic analysis) after miltefosine gel treatment on $L$. (V.) braziliensis-infected mice. ${ }^{(30,31)}$

The skin irritation observed at the application site, mainly due to the PMD isethionate cream, is a major concern. The design of a suitable PMD (isethionate or its free base form) delivery system to allow for controlled release, better absorption, higher therapeutic efficacy, and less toxicity is necessary. Different systems for PMD delivery - such as chitosan-coated niosomes (inPentasomes), mesoporous silica nanoparticles, and sugar-grafted liposomes - have been designed to treat leishmaniasis and other diseases, with interesting results..$^{(32,33)}$

In this study, we demonstrated that 3-PACK treatment using 6\% PMD isethionate cream was $67 \%$ effective in the treatment of CL caused by L. (V.) braziliensis. Ongoing work will improve the PMD isethionate formulation so that it is less irritating and more effective, and will also help to determine a dose-response using a larger number of animals. 


\section{ACKNOWLEDGEMENTS}

To ME Salazar and AM Vera for their assistance in conducting some antileishmanial experiments; to JA Osorio for animal welfare and technical assistance; and to the pathology department team for biopsy processing.

\section{AUTHORS' CONTRIBUTION}

BYM performed most of the experiments, provided intellectual content, and participated in the design of this work, analysis and interpretation of the data, and writing of the manuscript; JCM conducted the histopathological experiments, critically read the manuscript, and analysed the results; PE provided intellectual content, supervised the study, provided reagents and experimental instruction, and participated in the design of this work, analysis and interpretation of the data, and writing of the manuscript. The authors declare that they have no conflict of interest.

\section{REFERENCES}

1. Alvar J, Vélez ID, Bern C, Herrero M, Desjeux P, Cano J, et al. Leishmaniasis worldwide and global estimates of its incidence. PLoS One. 2012; 7(5): e35671.

2. Ramírez JL, Guevara P. Persistent infections by Leishmania (Viannia) braziliensis. Mem Inst Oswaldo Cruz. 1997; 92(3): 333-8.

3. Dantas ML, de Oliveira JMGC, Carvalho L, Passos ST, Queiroz A, Guimarães LH, et al. Comparative analysis of the tissue inflammatory response in human cutaneous and disseminated leishmaniasis. Mem Inst Oswaldo Cruz. 2014; 109(2): 202-9.

4. Sadeghian G, Ziaei H, Bidabadi LS, Baghbaderani AZ. Decreased effect of glucantime in cutaneous leishmaniasis complicated with secondary bacterial infection. Indian J Dermatol. 2011; 56(1): 37-9.

5. Conceição-Silva F, Leite-Silva J, Morgado FN. The binomial parasite-host immunity in the healing process and in reactivation of human tegumentary leishmaniasis. Front Microbiol. 2018; 9: 1308.

6. Burza S, Croft SL, Boelaert M. Leishmaniasis. Lancet. 2018; 392(10151): 951-70.

7. Cota GF, de Sousa MR, Fereguetti TO, Saleme PS, Alvarisa TK, Rabello A. The cure rate after placebo or no therapy in American cutaneous leishmaniasis: a systematic review and meta-analysis. PLoS One. 2016; 11(2): e0149697.

8. De Vries HJ, Reedijk SH, Schallig HD. Cutaneous leishmaniasis: recent developments in diagnosis and management. Am J Clin Dermatol. 2015; 16(2): 99-109.

9. Sosa N, Capitán Z, Nieto J, Nieto M, Calzada J, Paz H, et al. Randomized, double-blinded, phase 2 trial of WR 279,396 (paromomycin and gentamicin) for cutaneous leishmaniasis in Panama. Am J Trop Med Hyg. 2013; 89(3): 557-63. doi: 10.4269/ajtmh.12-0736.

10. Milstone AM, Passaretti CL, Perl TM. Chlorhexidine: expanding the armamentarium for infection control and prevention. Clin Infect Dis. 2008; 46(2): 274-81.

11. Arif T. Salicylic acid as a peeling agent: a comprehensive review. Clin Cosmet Investig Dermatol. 2015; 8: 455-61.

12. Yang G, Choi G, No JH. Antileishmanial mechanism of diamidines involves targeting Kinetoplasts. Antimicrob Agents Chemother. 2016; 60(11): 6828-36.

13. Christen JR, Bourreau E, Demar M, Lightburn E, Couppié P, Ginouvès $\mathrm{M}$, et al. Use of the intramuscular route to administer pentamidine isethionate in Leishmania guyanensis cutaneous leishmaniasis increases the risk of treatment failure. Travel Med Infect Dis. 2018; 24: 31-6.
14. Clark A, Hemmelgarn T, Danziger-Isakov L, Teusink A. Intravenous pentamidine for Pneumocystis carinii/jiroveci pneumonia prophylaxis in pediatric transplant patients. Pediatr Transplant. 2015; 19(3): 326-31.

15. Paine MF, Wang MZ, Generaux CN, Boykin DW, Wilson WD, De Koning HP, et al. Diamidines for human African trypanosomiasis. Curr Opin Investig Drugs. 2010; 11(8): 876-83.

16. Kotthaus J, Kotthaus J, Schade D, Schwering U, Hungeling H, Müller-Fielitz H, et al. New prodrugs of the antiprotozoal drug pentamidine. ChemMedChem. 2011; 6(12): 2233-42.

17. Soto J, Buffet P, Grogl M, Berman J. Successful treatment of Colombian cutaneous leishmaniasis with four injections of pentamidine. Am J Trop Med Hyg. 1994; 50(1): 107-11.

18. Andersen EM, Cruz-Saldarriaga M, Llanos-Cuentas A, Luz-Cjuno M, Echevarria J, Miranda-Verastegui C, et al. Comparison of meglumine antimoniate and pentamidine for peruvian cutaneous leishmaniasis. Am J Trop Med Hyg. 2005; 72(2): 133-7.

19. Robledo SM, Puerta JA, Muñoz DL, Guardo M, Vélez ID. Efficacy and tolerance of pentamidine for treatment of cutaneous leishmaniasis caused by $L$. (V) panamensis in Colombia. Biomedica. 2006; 26(Suppl. 1): 188-93.

20. Zheng WJ, Gao J, Wei Z, Zhou J, Chen YM. Facile fabrication of selfhealing carboxymethyl cellulose hydrogels. Eur Polym J. 2015; 72: 514-22.

21. OECD - Organisation for Economic Cooperation and Development. Test No. 404: acute dermal irritation/corrosion. OECD Guidelines for the Testing of Chemicals, Section 4. 2015. Available from: https://www.oecd-ilibrary.org/docserver/9789264242678en.pdf?expires $=1554131291 \& \mathrm{id}=\mathrm{id} \&$ acc $n a m e=0 \mathrm{cid} 54025470 \& \mathrm{ch}$ ecksum=6EEAC85F6A5746774828EF9C2456D598.

22. Roberts CD, Leaper DJ, Assadian O. The role of topical antiseptic agents within antimicrobial stewardship strategies for prevention and treatment of surgical site and chronic open wound infection. Adv Wound Care (New Rochelle). 2017; 6(2): 63-71.

23. Bryceson AD, Murphy A, Moody AH. Treatment of 'Old World' cutaneous leishmaniasis with aminosidine ointment: results of an open study in London. Trans R Soc Trop Med Hyg. 1994; 88(2): 226-8.

24. Miranda-Verástegui C, Llanos-Cuentas A, Arévalo I, Ward BJ, Matlashewski G. Randomized, double-blind clinical trial of topical imiquimod 5\% with parenteral meglumine antimoniate in the treatment of cutaneous leishmaniasis in Peru. Clin Infect Dis. 2005; 40(10): 1395-403.

25. López L, Vélez I, Asela C, Cruz C, Alves F, Robledo S, et al. A phase II study to evaluate the safety and efficacy of topical $3 \% \mathrm{am}$ photericin B cream (Anfoleish) for the treatment of uncomplicated cutaneous leishmaniasis in Colombia. PLoS Negl Trop Dis. 2018; 12(7): e0006653. doi: 10.1371/journal.pntd.0006653.

26. Lane ME. Skin penetration enhancers. Int J Pharm. 2013; 447 (1-2): 12-21.

27. Choy YB, Prausnitz MR. The rule of five for non-oral routes of drug delivery: ophthalmic, inhalation and transdermal. Pharm Res. 2011; 28(5): 943-8. doi: 10.1007/s11095-010-0292-6.

28. Comandolli-Wyrepkowski CD, Grafova I, Naiff MF, Avella M, Gentile G, Grafov A, et al. Topical treatment of experimental cutaneous leishmaniasis in golden hamster (Mesocricetus auratus) with formulations containing pentamidine. Acta Amaz. 2017; 47(1): 9-46.

29. Soto J, Paz D, Rivero D, Soto P, Quispe J, Toledo J, et al. Intralesional pentamidine: a novel therapy for single lesions of Bolivian cutaneous leishmaniasis. Am J Trop Med Hyg. 2016; 94(4): 852-6. 
30. Vera AM, Casadiego OA, Mantilla JC, Escobar P. Evaluation of ketoconazole formulations for topical use in cutaneous leishmaniasis caused by Leishmania (Viannia). Rev Peru Med Exp Salud Publica. 2018: 35(3): 476-82.

31. Neira LF, Peña DP, Vera AM, Mantilla JC, Escobar P. Leishmaniasis cutanea inducida por especies de Leishmania Viannia en ratones BALB/c y eficacia de un tratamiento tópico. Rev Univ Ind Santander Salud. 2019; 51(1): 33-42. doi: 10.18273/revsal.v51n1-2019004.
32. Rinaldi F, Seguella L, Gigli S, Hanieh PN, Del Favero E, Cantù $\mathrm{L}$, et al. inPentasomes: an innovative nose-to-brain pentamidine delivery blunts MPTP parkinsonism in mice. J Control Release. 2019; 294: 17-26. doi: 10.1016/j.jconrel.2018.12.007.

33. Peretti E, Miletto I, Stella B, Rocco F, Berlier G, Arpicco S. Strategies to obtain encapsulation and controlled release of pentamidine in mesoporous silica nanoparticles. Pharmaceutics. 2018; 10(4): pii: E195. doi: 10.3390/pharmaceutics10040195. 